\title{
Gran Bretaña y Estados Unidos
}

\author{
Por el Dr. RAUL FERRERO (1)
}

Entre las contadas constituciones de valor típico, que han servido de modelc a gran número de países, las de mayor trascendencia en el mundo occidental son la de Gran Bretaña y la de los Estados Unidos de América.

Ia constitución británica es el producto de una larga evolución, en la que la experiencia ha venido creando instituciones y modelándolas sabiamente, sin responder a esquemas previos. Difiere por ello sustancialmente de los sistemas de otros países, formados por virtud de una elaboración racional o bien por simple trasplante. Inglaterra ha sido la cuna de las instituciones democráticas modernas, tales como el Parlamento, el Gabinete Ministerial y el control del Presupuesto.

Posteriormente, el pensamiento trancés, siempre cartesiano, fundamentó cioctrinariamente dichas instituciones. Ha sistematizado y ha procurado dar un carácter orgánico a lo que era el fruto de una tradición peculiar, hecha de contrastes, de precedentes variados y de la necesidad de una tolerancia surgida del conflicto. La constitución británica, muestra en su evo. lución y en su estado actual una gran heterogeneidad de formas, explicable por el proceso histórico.

En cambio, la carta de los Estados Unidos tiene un carácter orgánico y su texto enuncia los principios que la inspiran.

\section{I.-EVOLUCION HISTORICA DE GRAN BRETAÑA}

De una sociedad de tipo estamental en el medioevo, Inglaterra pasó al parlamentarismo oligárgico en los siglos diecisiete y dieciocho. Por último, ya avanzado el siglo dieciocho, el sistema fue evolucionando hacia una democracia de tipo liberal y democrático.

Las instituciones britónicas tienen un doble origen: anglosajón y normando. Del periodo anglo-sajón, que abarca del siglo cinco a la conquiista normanda del siglo XI, merecen especial mención la Asamblea de Prin-

(1) Cateárático titular de Derecho Constitucional y de Derecho Internacional Público. Decano de la Facultad de Derecho y Ciencias Políticas de la Pontilicia Universidad Católica. Decano del Colegio de Abográos de Lima. 
cipales (witenagemot) que asesoraba al Rey, los gobernadores locales (aldermans) que muchas veces se transformaron en cargos hereditarios, y los representantes del poder central (sherifts).

Con la conquista normanda (1066) se introdujo el feudalismo económico y político. Guillermo despojó a los propietarios de tierras y entregó el dominio de ellas a los guerreros normandos. Los campesinos sajones. quedar $n$, en gran parte, bajo señores que habían recibido la tierra en feudo y no en propiedad. El Consilium o curia Regia se dividió en la práctica, en dos: el Gran Consejo y el Pequeño Consejo. El Gran Consejo, continuación del witenagemot transformado en un cuerpo de barones, vasallos feudales del Rey, se reunía raramente. El Pequeño Consejo, compuesto por los barones más ligados a la administración, asesoraba directamente al Rey y constituía el órgano de gobierno, pues el Gran Consejo sólo era convocado para aprobar subsidios extraordinarios. Los altos dignatarios eclesiásticos eran también barones. Por virtud de la idea feudal del pacto, los barones, o sea los grandes y medianos vasallos, representaban una limitación al poder real; éste admitía que ciertos actos no eran lega. les, por no estar basados en la costumbre del pueblo inglés. Los derechos del Rey se denominaban prerrogáiivas y los derechos reconocidos al pueblo exan llamados privilegios, voces que hasta hoy subsisten.

\section{Carta de la Coronación de Enrique I.}

A Guillermo le sucedió su hijo Guillermo II y a éste su hermano Enrique I. Al ascender al trono, en el año 1,100, fué obligado a declarar que no repetiría los actos arbitrarios cometidos por su hermano y antecesor Guillermo II. Gracias a este compromiso, llamado "Carta de la coronación", los barones lo reconocieron como Rey, desplazando nuevamente al primogénito de Guillermo I, el duque Roberto, que había permanecido gobemando Normandia.

\section{La Carta Magna.}

En 1,215 los barones impusieron al Rey Juan sin Tierra la firma del documento que recogía los principios consuetudinarios pre-existentes y afirmaba con precisión dos fundamentos: a) que existen leyes que el go. bierno debe acatar; b) que si el gobierno no las respeta, la nación puede derrocarlo. La carta dispone reiteradamente que las garantías que el Rey otorga a sus barones son extensivas a los vasallos de éstos, o sea que los barones paciaron para sí y también para el pueblo. Las claúsulas más importantes son las que prohiben que alguien sea apresado o desposeído sino por fallo de sus poress a según las leyes del país y la que dispane que todo impuesto será ccordado, necesariamente, por el Consejo común del reino. Este último principio sería enunciado más tarde como doctrina constitucional: "todo impuesto debe ser consentido por los contribuyentes representados en el Parlamento", o sea "no taxation without representotion". 


\section{Orígenes del Parlamento.}

Al gran consejo se le agregaron, a mediados del siglo trece, dos representantes de los caballeros de cada condado; a poco, se reconocíb representación a los burgos y ciudades, con lo que resultó una Asamblea de los tres estomentos del reino; "los que rezon, los que guerrean y los cque trabajan". Al finalizar el siglo existía ya configurado el parlamento, que prento se agrupó en dos cámaras estamentales: la de los Lores o barcnes y la de los Comunes, integrada ésta por los burgueses y los caballeros. Ei Rey convoca, suspende y disuelve el Parlamento, siendo su aprobación indispensable para que rija toda forma legislativa. El pequeño Consejo, integrado por los principales nobles, aminora el poder real cuando la personalidad del monarca, o su corta edad, lo permiten.

En el siglo catorce el Parlamento creó el "impeachment", procedimiento de acusación a los ministros que formulaba la Cámara de los Conunes ante la de los Lores y que podía terminar con la sentencia de mueste.

\section{El Estado moderno de los Tudor (gobierno conciliar $y$ absolutismo)}

En el siglo XV, bajo el gobierno de los Reyes Tudor, Inglaterra termina con el localismo medieval. Se forma un Estado nacional, centraliza. do, pero sin aniquilar las insituciones medievales; las que pasan a servir como agentes del estado. El "common law" afirma su preeminencia sobre el particularismo de las comarcas. Los Jueces reales extienden por doquiera la aplicución de un mismo derecho. El Porlamento actúa sometido al Rey y la única institución que podría haber hecho trente al absolutismo, es casi aniquilada: la Iglesia Católica. La clase media, formada por las profesiones liberales y los pequeños propietarios rurales, accede a un rapel relevante. El Consejo asume mayores funciones, adoptando la denominación de "Privy Council" integrado por mentes ilustres y hombres de voluntad decidida, extraídos de la clase media y que por ello sirven a la Corona con lealtad, puesto que le deben su posición. El Consejo tiene también funciones judiciales; una de sus comisiones, la llamada cómara es. trellada, constituye el tribunal central del Reino.

La época Tudor fue de gobiemo conciliar, pues la voluntad del Rey estuvo influída por el Consejo. Privado. A la vez, imperó el absolutismo, ya que el Parlamento carecía de independencia.

Los recursos de la Corona, aumentados por "donativos" logrados bajo forma voluntaria, le permiten diferir las convocatorias del Parlamento $y$ éste confiere al Rey la facultad de dictar normas jurídicas en Consejo, llamadas proclamas. Con Isabel, la docilidad del Parlamento se acentúa, en parte por el odio común al catolicismo y el creciente sentimiento nacionalista, que era anti-hispano y anti-papista. El pequeño consejo llamado consejo privado, adquiere una gran importancia como órgano permanente de la administración. Dado que sus componentes eran miembros de alguna de los dos cómaras ejercían una influencia dominante en el Poder Legislativo. Sin faltar a las formas, los Tudor gobernaron como monar- 
cas absolutos, aparentando que no hacían sino ejecutar las resoluciones del Parlamento. En realidad, mediante la creación de burgos, o sea atribuyendo representación a poblaciones sin importancia, y gracias al empleo de halagos y presiones, la Corona obtuvo la colaboración complaciente del Parlamento, tanto para las innovaciones religiosas como para evitar el control político.

\section{Lucha por la supremacía entre el Rey y el Parlamento.}

Jacobo I, primer rey de la casa Estuardo, tenía la convicción de gabernar por derecho divino, como creían los monarcas del continente. Ello entrañó una causa de conflicto con el Pcrlamento, algo rebelde desde los últimos años del reinado Tudor. La dinastía de los Lancaster había respetado los principios constitucionales. El período de los York y los Tudor fué de absolutismo, pero bajo formas acordadas por el Rey y el Parlamento.

La querella de Jacobo con el Parlamento duró todo su reinado (16031625). El conflicto hizo crisis al advenimiento de Carlos I, igualmente infatuado y con la desventaja de su debilidad de carácter y su limitada inteligencia. El primer Parlamento que convocó le negó los subsidios pedidos y acordó que debían reformarse los abusos, en especial la recaudación do impuestos ilegales que pretendían revivir usos feudales. De nada sirvió a la Corona disolver sucesivos Parlamentos, pues fué acentuándose el ánimo de reforma.

A la vez que el Parlamento negaba que el Rey fuera "lege solutus". los jueces, cuyo inspirador era el célebre Juez Coke, también jefe de la oposición en el Parlamento, cibraron una victoriosa campaña para imponer el predominio del common law sobre los tribunales de prerrogativas. El common law no es un derecho racional sinó un derecho histórico, cuya captación correcta por los jueces requiere gran aptitud y versación. La tesis parlamentarista se va construyendo en torno de la defensa de las libertades civiles inglesas, hecha por Elliot, Fim y Hampden y debía servir de base para la teoría del pacto social y de los derechos naturales, desarrollada más tarde por el racionalismo francés.

Las guerras con España y Francia, que habían obligado al Rey a imponer contribuciones ilegales, dejaron a la Corona en verdadera incpia. De otro lado, la resistencia contra la Iglesia oficial hizo progresos en Escocia $y$ gran parte de Inglaterra. Para evitar obstrucciones, Carlos I disolvió el Parlamento y se negó a convocarlo durante once años.

El documento más importante de la época es la Petición de Derechos. impuesta a Carlos I en 1628 en señal de aceptación de las exigencias parlamentarias. Constituye una restauración del derecho violado y se afirma en los principios de la Carta Magna. Prohibe establecer impuestos sin el consentimiento del Parlamento, efectuar detenciones y juicios en desacuerdo con la ley común, aplicar la ley marcial u obligar al alojamiento de soldados en los domicilios privados. La abolición de lá Cámara Estrellada y demás tribunales de prerrogativa, en 1641, confirmó la supremacía del common law. La ejecución del Ministro Strafford, el mismo año, sentó el 
principio de la responsabilidad de los Ministros ante el Parlamento, mediante el proceso criminal del "impeachment" que podia terminar en una cordena de muerte y que siglos más tarde se humanizaría al trocarse en simple voto de censura.

La guerra civil terminó con la derrota y la decapitación de Carlos I. La dictadura militarista de Cromwell abolió la monarquía y proclamó la "Commonwealth", o sea comunidad libre gobernada por los representantes del pueblo (la expresión equivale a república).

\section{La Restauración.}

La repulsa al gobierno arbitrario de Cromwell, condujo a la restauración de la monarquía en 1660, poco después de haber muerto el dictador. Bajo el reinado de Carlos II se promulgó la Ley de Habeas Corpus, que estubleció el procedimiento para hacer efectiva la garantía de que nadié puede ser detenido sin mandato judicial, debiendo ser presentado el cuerpo o persona del preso ante el tribunal que amparara la denuncia de secuestro. También es importante consignar el nacimiento de los partidos tories y whigs, con motivo del proyecto de ley para excluir a los católicos del trono.

Los tories, que más tarde se llamarían conservadores, eran descendientes de los caballeros realistas, propietarios rurales, anglicanos, cler cales y enemigos del catolicismo y del puritanismo. Exan partidarios de una Corona fuerte, sin perjuicio de los fueros del Parlamento. Los whigs, que se denominarían más tarde liberales, descendían de los antiguos particlarios de Cromwell; eran puritanos y partidarios de la tolerancia religiosa para los protestantes. Estaban vinculados al comercio y $\propto$ la industria; luchaban por reducir los derechos de la Corona y se basaban, aunque no lo proclamaran claramente, en la teoría del pacto social.

\section{De la revolución de 1688 a la reforma de 1832.}

La revolución de 1688, denominada "Gloriosa Revolución" confirmó el principio de la soberanía de la Nación, puesto que derrocó a Jacobo II invocando que éste había violado la Constitución. La ley que declaró la vacancia del trono expresaba que el Rey había tratado de subvertir la Constitución del Reino, rompiendo el contrato originario entre el rey y el pueblo al violar las leyes fundamentales.

Comenzó el gobiemo parlamentario de base oligárquica y la Corona asumić un carócter simbólico, impersonal, de encarnación del Estado. Dos importantes documentos hacen desaparecer los restos de la doctrina del derecho divino y configuran la monarquía constitucional: la Declaración de Derechos, en 1689, y el Acta de Establecimiento, en 1701. La Declaración de Derechos, que Guillermo y María tuvieron que jurar como condición para ascender al trono, enumeraba los actos arbitrarios de Jacubo II y los declaraba ilegales; promulgada luego como Estatuto con algunas adiciones, es el documento mós valioso de la historia inglesa des. 
pliés de la Carta Magna e implica el reconocimiento de la supremacía do la ley y de la Soberanía Nacional. En el Acta de Establecimiento, cuyo principal objeto fue conceder el trono de Inglaterra a la Casa de Hanover, se insertaron importantes disposiciones de carácter orgánico, tales como la garartía de inamovilidad de los jueces "mientras observen buena conducta", y la norma de que todos los asuntos de Gobierno fueran tratados en el Consejo Privado, cuyos miembros debían firmar las resoluciones de su ramo para dejar constancia de su responsabilidad.

En el siglo dieciocho nació el Gabinete, la institución más importante ciesde aquella época. Bajo el reinado de Ana (1702-1714) se hizo costumbre tratar los asuntos gubernativos no con el pleno del Consejo Privado sinc en el Subcomité compuesto por los consejeros que desempeñaban los cargos principales. Este subcomité o Gabinete fué substituyendo al Consejo Privado en cuanto órgano de deliberación y dirección en casi todos los asuntos del Estado. A partir de Jorge I, que no asistía a las reuniones del Gabinete porque no entendía las instituciones, ni el idioma, ni los problemas británicos, los reyes fueron dejando que las sesiones se realizaran sin su presencia lo que originó el espiritu de cuerpo del gabinete ministe. rial y su homogeneidad política, así como la creciente relación con la mayoría parlamentaria.

Reformas electorales de 1832, 1867, 1884 y 1918; disminución dal poder de la oligarquía y de los Lores.

En líneas generales, el sistema electoral anterior a 1832 era el mis mo que el de la Edad Media. Ciudades despobladas conservaban el derecho de enviar representantes a los Comunes, en tanto que importantes poblaciones surgidas en la era industrial carecían de representación. Un sijtema arbitrario y feudal daba a los terratenientes predominio sobre los industriales y sobre la creciente clase media y el pueblo. Las reformas electorales de 1832, 1867 y 1884 ampliaron progresivamente la masa de electores, transformando la oligarquía en una democracia restringida. En 1918 se estableció el sufragio universal, poniéndose término a las discri. minaciones por razón de propiedad, domicilio o familia.

El Parlamento ganó en autoridad frente al pueblo y frente a la Corona. En cambio la fué perdiendo frente al Gabinete, cuya cabeza, el Primer Ministro, ha pasado a ser la clave del gobierno. $E_{n}$ 1911, se despojó a los Lores de la facultad de revisar las leyes de carácter financiero, dejárciose a la Cámara Alta sólo un voto suspensivo de dos años respecto de las demás leyes. Sus funciones actuales son, predominantemente, judiciales y de fiscalización del ejecuivivo. La supremacía de la Cámara de los Comunes es completa, al punto de que el Primer Ministro debe ser diputado y es poco frecuente que se encargue alguna cartera ministerial a un miembro de la Cámara Alta. El reciente caso de Lord Home, que renunció a su título nobiliario para asumir el cargo de premier y postular a los Comunes, es muy ilustrativo. 


\section{II.-SISTEMA CONSTTtUCIONAL DE GRAN BRETAÑA}

Flexibilidad y corácter consuetuitinario.

Las particularidades más notables de la constitución británica son las siguientes:

a) que no existen leyes especialmente caracterizadas como constitucionales;

b) que las reglas consuetudinarias. pese a ser desprovistas de sancion legal, son observadas escrupulosamente, como convenciones nacidas de la costumbre, o sea de la repetición de los precelentes.

La constitución británica, por tanto, es el arquetipo de las constituciones flexibles, o sea que se reforma por el mismo órgano y el mismo procedimiento que las leyes ordinarias. En base a su ejemplo, Bryce estableció la distinción entre carias rígidas y cartas flexibles. Por excepción, la ley que regula las relaciones entre el Reino Unido y los Dominios (Fstatuto de Westminster) no podría ser alterada por acto unilateral del Parlamento. Ia constitución inglesa, acabada expresión de lo tradicional y evolutivo, es un desarrollo de decisiones parciaies y de usos, costumbres y precedentes.

\section{Principios fundamentales.}

Los principios fundamentales del sistema británico son los siguientes:

a) el liberalismo, caracterizado por su respeto a los derechos indi. viduales, el Estado de derecho y la separación de poderes;

b) la amplitud de facultades del Farlamento, el que no está limitado por la constitución y puede dictar reglas generales o regias individuales sin limitación (desde abolir la Corona hasia declarar nulo un matrimonio, en hipóiesis), si bien el Gabinete es en la práctica quien dirige la creación de las leyes;

c) la democracia representativa, según la cual es el sufragio pupular la then:o de: gobierno y la voluntad que decide, por acto plebiscitario, quieres dieben asumir el Gobierno, ya que, al votar por los representantes parlamentario:i, to que interesa al elector es cuál será el equipo gobernante.

\section{Fuentes ċel Derecho Constitucional Británico.}

Por ausencia de una constitución formal, o sea de una carta orgánica, el régimen de gobierno se basa en las fuentes siguientes:

A) La legislación (statule law), cuyos principales documentos son la Carta Magna, de 1215, la Declaración de Derechos, de 1689, el Acta de Establecimiento, de 1701, las Āctas de Unión de Escocia, de 1707, e Irlanda, de 1800, y el Estatuto de Westminster, de 1931.

B) Las decisiones jưdiciales (case law o common law), que crean 
normas o interpretan el derecho legislado, como sucede con el derecho do reunión y otros.

C) Las convenciones, o sea los usos y precedentes que han dado origen, $\sin$ ley alguna, a instituciones tales como el Gabinete Ministerial, el Primer Ministro, la oposición de Su Majestad, la convocatoria anual del Parlamento, la responsabilidad ministerial, la disolución de la Cámara de los Comunes, la nulidad del veto real. Dichas convenciones son esenciales a la estructura constilucional y su violación constituiría una verdadera ruptura revolucionaria.

\section{La Corona.}

Las palabras "Rey" o "Corona" son usadas indistintamente para expresar al Estado. A la vez, significa Poder Ejecutivo, corrientemente, tal como en muchos países se menciona al Supremo Gobierno. La palabra Corona da concreción a la unidad jurídica y política y vínculo de los tres poderes. A la Corona se le imputan los actos jurídicos más diversos, pues al Ejecutivo se le denomina rey en Consejo; al Legislativo, rey en Parlamento; $y$ al Judicial, rey en su Tribunal.

También se entiende por Corona una de las instituciones del poder ejecutivo, integrada por el Rey y sus Ministros. El Rey es irresponsable; carece de veto pero su firma es la que sanciona las leyes; puede disolver el Parlamento a requerimiento del Primer Ministro; es origen de toda jurisdicción en lo judicial y puede conceder gracia; es la fuente de honores y dignidades; confiere la representación diplomática y gobierna teóricamente la Iglesia Anglicana. Sobre todo es vínculo y símbolo de la comunidad británica de naciones (British Commonwealth).

\section{El Gabinete.}

Los Ministros son nombrados por el Rey, a propuesta del Primer Ministro La composición del ministerio estó completamente al arbitrio del Premier, quien no tiene otras limitaciones que las que derivan de su partido, pues ha de escoger dentro de la mayoría de la Cámara de los Comunes; algunas veces se confía Ministerios a los Lores. No todos los componentes del Gabinete llevan el título de Ministros, pues algunos cargos son residuos del sistema vetusto, tales como el Primer Lord del Almirantazgo, el Lord Presidente de la Junta de Comercio y el Lord del Sello Privado. En circunstancias especiales puede crearse dentro del Gabinete un Comité o Gabinete restringido que concentra las responsabilidades de conducir la guerra.

Además de actuar como Ministerio, el Gabinete funciona como integrante del "Privy Council", organismo del que surgió el Gabinete como Junta restringida o Comité. El Privy Council tiene alrededor de $300 \mathrm{miem}$ bros, designados casi siempre a título honorífico; le corresponde la mera formalidad de dar fuerza jurídica a las decisiones gubernamentales, que así revisten el carácter de leyes virtuales, adoptadas por el Rey en su Consejo. 
Modificando el "rule of law" o imperio del Derecho, los poderes discrecionales han venido aumentando notablemente en favor de los departa. mentos administrativos. Además de la legislación delegada, debe considerarse que en Gran Bretaña no es fácil recurrir al poder judicial contra los excesos de la Administración, a diferencia del sistema de los Estados Unidos o de la amplia jurisdicción contencioso-administrativa imperante en Francia. La separación de poderes no se abserva en la próctica, ya que el Gabinete ejerce dominio sobre el Parlamento y éste le delega con frecuer. cia la facuitad de legislar bajo forma de decretos. Por cierto, el Parlamento retiene la facultad de fiscalizar, enmendar y hasta anular los actos del Ejecutivo, pero la próctica de la delegación legislativa ha alterado la estruclira tradicional de los poderes. En cuanto a la dirección del Parlamento por el Gabinete, lograda por disciplina de partido y mediante el control del orden del día por el Gobierno, debe advertirse que la iniciativa de las leyes es ejercida casi totalmente por el Gabinete, a tal purto que se puede afirmar que es éste quien legisla con el consentimiento $y$ la interverición moderadora del Parlamento.

\section{El Primer Ministro.}

Es el Jefe del Gobierno y la clave del Gabinete, equiparable al Presidente de los Estados Unidos. En la práctica, el pueblo, al votar por los miembros del Parlamento, sabe quién es la personalidad relevante que ejercerá el gobierno. Es el leader del Parlamento y puede emplear la organización de su partido contra los colegas disidentes de su opinión. Si bien es responsable ante el Parlamento, su derecho a pedir al Rey la disolución de la Cámara le $\mathrm{d} x$ una influencia muy grande. La dirección del Estado se halla en sus manos, no obstante ser el Parlamento un verdadero soberano. Es usual que los autores británicos traten al Parlamento como soberano porque, no existiendo propiamente una Constitución, goza de facultades legislativas ilimitadas.

En realidad, el Gabinete recibe su mandato del pueblo, en las elecciones generales, ya que los electores votan por los parlamentarios que pertenecen al partido de sus preferencias a fin de asegurar la nominación del equipo gobernante. El poder ejecutivo se asienta en la opinión públicc: y vive cuidando de conservarla a su favor.

\section{El Parlamento}

Se dice que el Parlamento es soberano porque, no existiendo propiamente una Constitución, las facultades legislativas son ilimitadas o sea que el Parlamento goza de un poder jurídico de total amplitud.

Tiene una duración máxima de cinco años y goza de gran prestigio, sobre todo la Cámara de los Comunes, en la cual reside el poder y de cuyo seno salen prácticamente todos los Ministros pues no es frecuente que ejerza una cartera algún miembro de la Cámara de los Lores. Numerosos representantes, además del distrito electoral, llevan en la prácti- 
ca la representación de los grupos económicos con los que se hallan vinculacios. Casi todos los distritos eligen solamento un diputado, siendo raros los que tienen derecho a designar dos o más. No existe representación de la minoría como sistema previo, ya que cada distrito elige solamente a los mayoritarios. Pero, dada las diversas tendencias de los distritos electorales, la oposición se halla representada por quienes obtuvieron la mayoríc en aquellos distritos en que predominaba el partido opuesto al que ha ganado el poder. El sistema uninominal, o sea no proporcional, explica que la composición de la Cámara refleje muy desproporcionadamen. te las corrientes parlidistas.

La opcsición juega un papel fundamental. Ocupa los asientos situados al frente del escaño del Gobierno (Government Front Bench y Oppositien Front Bench). Su líder percibe un sueldo anual, a fin de hacer posible que se dedique a controlar al Gabinete.

El Presidente (Speaker) tiene la facultad do seleccionar las enmiendo.s presentadas a una moción o a un proyecto de ley, de modo que sean cuíatidas sólo las principales o de índo (f́caltad llamada de "canguro" en el lenguaje corrienie).

\section{Bipartidisño.}

Desde tres siglos atrós el poder se alterna entre dos grandes partidos. Hasta la presente centuria eran el conservador y el liberal. Desde háce medio siglo, el partido laborista hace la baianza del poder con el pariido conservador, pues los liberales no alcanzan un volumen de votos que les permita ejercer influencia.

La "Oposición de Su Majestad" es la más notable contribución del pasado siglo. El partido que se halla fuera del poder es reconocido como leal a las instituciones del país y en situación de espera para alcanzar el gobierno, cuando alcance la mayoría de los sufragios.

El rígimen de partidos se ha tornado consubstancial a la democracia británica. Les partidos cristalizan el sufragio, ofreciendo el pueblo en caj̀n elección dos equipos de gobierno y dos programas definidos. Sobro todo, preparan a los hombres mejores en la carrera pública, seleccionándolos desde las aulas universitarias o las organizaciones sindicales y brindándoles oportunidad de pariicipar una y stra vez, según sean sus éxitos o eventuales fracasos. El sistema de partidos, con disciplina sobre los grupos par. lamentarios mediante los célebres whips, asegura al Gabinete una mayoria sólida y constante, a la vez que permite influir sobre la opinión en todo mo. mento, captando los votos desde muchos años antes de la elección. Una convención anual es la máxima autoridad, $\alpha$ la que se agrega una red de asociaciones locales, un consejo central y un comité ejecutivo. El debate parlamentario es un diálogo contínuc entre oposición y gobierno, con la convicción general de qus la oposición realiza un juego leal e indispensable. El líder de cada partido concreta o personaliza la aspiración a gobernar y constituye un candidato alterno al poder, señalado desde meses o años antes a la celebración de comicios. 


\section{Constitución de los Estados Unidos de América}

\section{Anlecedentes de la Federación.}

Al iniciarse el movimiento de emancipación de Estados Unidos da Norte América, en 1776, existían 13 colonias o comunidades, fundadas en disintas épocas y sin vinculación política entre sí. En conjunto, su ierritorio abarcaba la región situada entre el Atláníico y los Montes Alleçhanis, - sea menus de una cuarta parte de la actual extensión del país. La Coro$\mathrm{n} x$ designaba a los gobernadores, excepto en Connecticut $\mathrm{y}$ Rhode Ísland que, por Real Curta, gozaban del privilegio de elegir a sus gobernadores. Una Asamblea representativa dictaba leyes en cada colonia $\mathrm{y}$ las leyes del parlamento británico regían sólo en aquellos casos en que el Parlaniento había ordenado su aplicación en las colonias. Al igual que en la Metrópoli el common law normaba las relaciones jurídicas. Salvo en el orden comercial, la autoridad inglesa era laxa. Las comunicaciones eran escasis y cada colonia mantenía relación más bien con la Metrópoli que con las colonias distantes.

El año 1776, para hacer frente común contra los impuestos esiablecicos inconsultamente, las trece colonias, o sea Massachusetis, New Hampshire, Rhode Island, Connecticut, New York, New Jersey, Pannsyivania, Delaware, Maryland, Virginia, North Carolina, South Carolina y Georgia, acordaron designar delegados a un "Congreso Continentai" para consiiuir. una unión. El 4 de julio de dicho año, el Congreso reunido en Filadelfia con asistencia de delegaciones de doce colonias, aprobó la célebre "Declaración de Independencia", redaciada principalmente por Jefferson.

La Declaración fue firmada a poco por Rhode Island, que no había concurrido al acto. Constituye una afirmación de verdades de derecho natural que los padres de la patria consideraban evidentes, tales como la libertad, la igualdad esencial de todos los hombres, su derecho a la "búsqueda de la felicidad", el asentimiento de los gobernados como única fuente dal poder y el derecho a cambiar de gobierno mediante lx rebelión cuando éste se vuelve tiránico.

Al año siguiente, o sea en 1777, se convino un pacto de federación y unión perpétua. Cada estado conservaba su soberanía, estableciéndose un Congreso como órgano común para la guerra. Los "Artículos de la Confederación" fueron aprobados por cada uno de los estados. Pero la 
falta de Poder Ejecutivo y las débiles atribuciones del gobierno congresional entorpecieron la conducción de la guerra y determinaron un estado anárquico durante los primeros años de vida independiente.

La situación de desgobierno impuso rectificar tan exagerada autonomía. A iniciativa de Virginia, cinco Estados designaron delegados para una reunión en Annápolis, Estado de Maryland, a fin de contemplar una organización más firme. La Convención así reunida recomendó al Congreso y a los Estados que se convocara unx Convención más amplia, con delegados de todos los Estados. La Convención se reunió el año 1786 en la ciudad de Filadelfia; aunque debía limitarse a enmendar los Artículos de la Confederación, acordó reunirse en sesiones reservadas hasta dictar una constitución para los Estados Unidos, excediéndose del objeto de la convocatoria. La Constitución fué promulgada en 1787 y quedó ratificada por todos los Estados dos años después.

La Convención de Filadelfia fué presidida por Washington y reunió a los hombres más ilustres por el saber y la virtud. La mayor gravitación ideclógica fué, sin duda, la de Tomós Jefferson, pese a encontrarse $\alpha$ cargo de una misión diplomática en Europa. Muy pronto, la Constitución fué modificada en algunos de sus artículos. Para las enmiendas se requiere el voto conforme de dos tercios de cada Cámara, así como la ratificación por el cuerpo legislativo de las tres cuartas partes de los Estados.

Esta rigidez del texto constitucional tiene mucho de aparente; en la próctica, la evolución del derecho constitucional ha sido lograda insensiblemente por medio de la interpretación de la Corte Suprema, la cual ha alterado el sentido literal de muchos preceptos. La simplicidad del iexto (éste no excede de 7,500 palabras) ha favorecido la flexibilidad en la interpretación jurisprudencial, que ha venido expresando el sentido en que deben entenderse hoy el espíritu y la letra de los preceptos constitucionales.

Lo característico de una constitución federal es que integra varias unidades territoriales en una organización conjunta. El substratum es un pueblo con soberanía única hacia el interior y hacia el exterior, pero apa. rentemente existe en el interior una doble soberanía por los Esiados miembros. Ciertas materias son legisladas por el conjunto federal y otras son de competencia de los Estados particulares. Fara la delimilación formal de competencias lo usual consiste en enumerar las materias que son competencia de la Federación, como sucede en los Estados Unidos y en Alemania, quedando en la esfera de cada Estado miembro las demás compotencias. El sistema canadiense es una excepción, pues enumera los pcderes de los Estados y deja el resto de competencias librado a la Federación.

En cuanto a la ejecución de lo legislado por la Federación existen dos sistemas: En Norteamérica, se cumple por los órganos federales, o sea de modo inmediato, en tanto que en Suiza la ejecución tiene lugar de modo mediato a través de los Estados miembros, los cuales operan como órganos federales en dichos aspectos. 


\section{Gobierno dual: órganos federales y estatales.}

La técnica de la constitución es original, en razón de las circunstancias históricas que motivaron la unión y del recelo de cada estado para montener al mínimo los poderes federales. En efecto, los poderes de la Unión están enumerados, en tanto que los poderes de los estados están sokreentendjdos. La clave del federalismo norteamericano es la enmienda Diez, según la cual corresponden a los estados o al pueblo todas las facultades que la Constitución no delega a los órganos de la Unión. Inicialmente, se concibió al gobierno federal como una simple agencia común para las relaciones. Pero más tarde, en una evolución acentuada desde la guerra de secesión, la Unión ha venido gunando atribuciones y afirmando la homogeneidad y el centralismo en cuanto fueran necesarios.

Paralelamente a los ćrganos federales, existen en cada estado órganos propios (legislativo, ejecutivo y judicial) debidamente organizados por la Constitución adoptada por cada estado. Ello supone doble administración y la coexistencia de dos clases de normas y de autoridades.

\section{Poder Legislativo Federal}

El Congreso está compuesto por el Senado y la Cámara de Representantes. Los senadores son elegidos por seis años, en tanto que los repre. sentantes lo son cada dos años por el pueblo de los diferentes Estados "proporcionalmente a su población". Para ser elegido se necesita tener 25 años y ser residente en el Estado. La elección se hace por distritos, a razón de un representante por cada uno de ellos.

A base del censo que se practica cada diez años, una ley fija el número total de representantes y los distribuye entre los Estados en proporción. Cada Estado señala sus distritos electorales, así como los requisitos de los votantes. Según haya sido el crecimiento demográfico en la última década, los Estados pierden o ganan bancas en la Cámara de Representantes. Actualmente, la ley fija en 435 el número de representanies.

El Senado Federal se renueva por tercios cada dos años y está computsto de senadores elegidos por voto popular a razón de dos por cada Estado, sin que importe la población, pues los constituyentes idearon dicha distribución para mantener garantizada la equiparidad de los Estados. Su Presidente es el Vice-Presidente de la República y vota solamente en caso de empate. Para ser senador se requiere tener 30 años de edad y residencia en el Estado respectivo. El Senado tiene mayor importancia que la Cámara de Representantes, especialmente porque el mandato de los senadores dura cada 6 años, Jo que permite una política más definida. El grar poder de la Cámara de Representontes para influir en política radica, principalmente, en que es de su competencia la iniciativa en materia de tributación, que luego revisa el Senado.

\section{Atribuciones del Senado}

Le corresponde aprobar los tratados internacionales por una mayoría conforme de dos tercios y prestar su ratificación a los nombramientos 
de los altos funcionarios. Entre éstos se considera a los Ministros, a quienes se denomina Secretarios porque para la Constitución son simples jefes de los Departamentos fáministrativos. El Senado ratifica los nombramientos de Ernbajadores, Ministros y Cónsules, así como los de los magistrados judiciales. Por medio de sus Comisiones, ejerce gran influencia en la vida nacional. Tiene el carácter de Tribunal de Justicia para juzgar a los altos funcionarios, inclusive el Presidente, a los propios Senadores, a los miembros de la Cámara de Representantes $y \propto$ los Ministras. La acusación la hace la Cámara de Representantes y la declaración de culpabilidad requiere reunir dos tercios de los votos del Senado.

Las credenciales de los Senadores, lo mismo que las de los Repre. sentantes, son revisadas por sus respectivas Cámaras, que califican su validez para incorporar o no al elegido.

\section{Funcionamiento de las Cámaras}

El hecho de que el mandato senatorial sea de seis años y el de los representantes sólo de dos, hace más selecta la composición del Senado y le permite fijar una política contínua. El Presidente de la Cámara de Representantes tiene el nombre de "speaker" como rezago de la tradición britćnica. Los diferentes asuntos se entregan al estudio de Comisiones; éstas tienen una gran importancia, pues su dictamen es generalmente consagrado por la Cámara. Para las cuestiones más importantes se hace predominar en la Comisión a personas del partido mayoritario, pero en general la composición de las Comisiones es acertada y sirve para que un personal idóneo trate los asuntos con conocimiento, atenuando así los peligros de la improvisación popular, ya que la función parlamentaria es, en todo el mundo, una de las pocas para cuyo desempeño no se requiere título académico o profesional. Se puede requerir y sancionar a los miembros de las Cámaras para que concurran a sesiones en los casos en que, por motivos políticos, quieran ausentarse para privar de quórum.

\section{A Congreso Federal.}

Ambas Cámaras son iguales; en caso de discrepancia sobre un pro. yecto de ley, se nombra una Comisión mixta. Es competencia del congreso la dación de las leyes, para cuya vigencia se requiere la aprobación por ambas Cámaras y su promulgación por el Poder Ejecutivo; la regulación del comercio interestatal; la fijación de aranceles aduaneros; la contratación de empréstitos y sus condiciones; la legislación laboral federal, la organización de los servicios de Correos, Telégrafos, Ejército y Marina, así como pronunciarse sobre la declaración de guerra y la concertación de la paz. El sistema monetario debe ser regulado por el Congreso Federal. que resuelve el tipo y la acuñación de la moneda, así como la emisión do papel moneda. El Congreso determina, igualmente, los lugares en que deben establecerse en cada Estado los Tribunales de Justicia Federal.

El Congreso Federal es la autoridad gubernativa del Distrito Federal de Washington, por ser la Capital de la Unión, y le compete la legisla- 
ción sobre dicho distrito. Cuando el Estado Federal adquiere propiedades, cualquiera que sea el Estado en que estén radicadas, sea para arsenales, astilleros, fortificaciones o servicios, ejerce jurisdicción sobre ellas con indeperdencia de la legislación local. En materia monetaria, legisla sobre el sistema de la Reserva Federal, o sea el Banco nacional.

\section{El Fode: Ejecutívo Federal.}

El Fresidente de la República tiene muy amplias iacultades, inclusive el de observar las leyes. Según la ley de sucesión, aprobada en 1947, en defecto del Vice-Presidente, lo reemplazon, por orden, el Presidente de la Cómara de Representantes y el Presidente temporal del Senado debiendo realizarse elecciones si vacaran la Presidencia y la Vicepresidencia. Son miembros del Poder Ejecutivo, aún cuando la Constitución no los mentione como iales, los Secretarios o Jefes de los Diez Departamentos de la Administración Pública. Son nombrados por el Presidente con aprobación del Senado, cue casi nunca la niega. Removerlos es atribución exclusiva del Presidente. En conjunto se les denomina Gabinete, pero la reunión de Secretarios carece de atribuciones y no forma un cuerpo político ni frente al Congreso ni frente al Jefe del Estado. No tiene otra presidencia que la de éste. Los Ministras no pueden ser interpelados ni pueden dirigirse a las Cámaras.

Tanto el Presidente como el Vire-Presidente, duron en su cargo cuairo años y son elegidos por sufragio virtualmente directo. La forma de elección constituye un cnacronismo y se debe a gue la Constitución estableció la elección indirecta, en parte porque los patricios fundadores desconfiaban dol juicio popular $y$ en parte porque se quizo subrayar el carácter federalivo dundo a cada Estado una expresión aislada. En las elecciones generales, o sea cada cuatro años, se elige ciudadanos llamados electores ó compromisarios, los cuales se reúnen en colegios en la capital de cada Estado y emiten su voto para Presidente y Vice-Presidente. Actualmente, los compromisarios son elegidos bajo el mismo lema partidista del candidato presidencial, de modo que su posterior reunión es una mera formalidad, pues hon recibido un mandato moral y consideran que no debe cambiarse la decisión popular.

Lx reâistribución de bancas cada diez años, conforme al censo de pobiación, afecta también la participación de cada Estado en el Colegio Elecioral para designar Presidente de la República, pues el número de compromisarios o electores es igual al de representantes y senadores del Estado. Algunas veces, debido a la insatisfacción de ciertas aspiraciones, uros cuantos compromisarios anuncian antes de su elección que no votarán par el candidato presidencial de su partido y que harán uso de la libertad de decisión que la Constitución reconoce. No es raro que los adherentes a un partido voten por la lista de represeniantes que el partido recomienda y, a la vez, otorguen su voto a los compromisarios del candidato presidencial opuesto al de su partido. Tal fue el caso resonante que se produjo a favor de Eisenhower por dos veces. Propiamente, el Colegio Electoral no celebra reunión nacional, los compromisarios de cada Estado 
se reúnen en la capital local, el lunes que sigue al segundo miércoles de diciembre. La relación de sus votos es remitida al Senado. Luego el Congreso realiza el cómputo y proclama oficialmente a los que hayan obtenido la mayoría absoluta de todos los votos. Dado el hecho de existir sólo dos grandes partidos, uno de los candidatos logra siempre mayoría absoluta.

En teoría, nada impide que el Colegio Electoral designe triuntado: al candidato que alcanzó el segundo lugar en votos populares. En 1888. por ejemplo, Cleveland fue elegido Presidente no obstante tener por rezpaldo una votación popular ligeramente menor que la que apoyaba a su contendor. El proyecto Lodge-Gosset ha ideado un sistema menos defectuoso, que consistiría en atribuir a cada candidato un número de votos electorales que guarde proporción con los sufragios populares. En dicha forma, cada Estado reflejaría la proporción existente en los votos populares. En nuestra opinión, la madurez política del pueblo estadounidense hace poco menos que imposible que los compromisarios escamoteen la decisión ciudadana, por lo que, pese a lo anacrónico del sistema imperante, la elección presidencial se realiza en la práctica, por sufragio popular directo. La opinión pública y los propios gobernantes acatan al ganador desde el momento de conocerse el veredicto popular.

La Constitución ha previsto que ningún candidato alcance la mayoría absoluta de votos electorales, caso que no se presenta desdo hace cien años. En tal evento corresponde a la Cámara de Representantes elegir al Presidente entre los tres que hayan obtenido mayor votación. Se requiere para ello la mayoría absoluta con un quórum de dos terceras partes de los Estados, pues el voto se computa en tal caso por Estados. Los representantes de cada Estado emiten un voto conjunto.

El Vice-Presidente de la República asume la Presidencia por inccpacidad, renuncia, destitución ó muerte del Presidente. Es Presidente del Serado, lo que le da valiosa práctica política y un relieve constante. Si ninguno de los candidatos a Vicepresidente lograra mayoría electoral, corresporde al Senado practicar la elección.

Corresponde al Presidente la ejecución de las leyes, la iniciativa exclusiva del Presupuesto, el mantenimiento del orden, la celebración de tratados internacionales, que luego debe ratificar el Congreso Federal, y la designación de los funcionarios y empleados públicos, inclusive los Secretarios ó Ministros. Los Jueces y los funcionarios de mayor jerarquía requieren la ratificación del Senado. El Presidente ejerce el comando de la fuerza armada $y$ tiene el derecho de indulto.

Puede devolver con observaciones una ley y ésta no entra en vigor sino en caso que el Congreso insista por mayoría especial de dos tercios de cada Cámara, en votación nominal, lo que hace casi imposible sobrepasar la objeción presidencial, impropiamente llamada veto. Cuando media delegación expresa del Congreso, el Presidente puede legislar. No tiene facultad de remitir proyectos de Ley, pero recomienda al Congreso, por medio de mensajes, la dación de las leyes que cree convenientes. En el mensaje de instalación del Congreso puntualiza, de ordinario, las diver- 
sas leyes que solicita sean dictadas, sin perjuicio de dirigir mensajes posteriores recomendando la expedición de determinadas leyes. En lo referente al Presupuesto tiene inciativa de modo exclusivo y la ejerce a través del "Bureau of the Budget". No es raro que una iniciativa saludable sea aprobada con el voto de los representantes del partido opositor.

\section{Poder Judicial Fodoral.}

Conoce los casos de comercio entre los Estados, de almirantazgo ó navegación, de quiebras, inmigración, etc. La Primera Instancia está constituída por los tribunales federales de distrito, cuya demarcación no siempre coincide con los límites de los Estados. La segunda Instancia, está constituida por diez Cortes de Circuito; generalmente, un circuito judicial comprende varios Estados y en algunos casos está formado por un solo Fatado de importancio, como New York. Tercera Instancia, la constituye la Corte Suprema Federal. que tiene nueve miembros. En muchos casos, por razón de su naturaleza, se recurre a la Corte Suprema como Segunda Instancia, sin acudir previamente a las Cortes de Circuito, o bien, como sucede con los diplomáticos extranjeros o cuando es parto un Eatado, se recurro on primera instancia. Es poco trecuente seguir las tres instancias.

\section{Racionalidad y Estado do Derecho}

Los Estados Unidos son el típico Estado de Derecho, con imperio de la juridicidad y no sólo de la legalidad, pues el Tribunal Supremo recurre a los principios generales del Derecho cuando interpreta la Carta Fundamental para establecer si determinada ley no está de acuerdo con ella. La Constitución de los Estados Unidos tiene el carácter de un compromiso, pues, de un lado, afirma el gobierno on la voluntad del pueblo, on tanto que, de otro lado, previene contra la demagogia y la precipitación purlamentaria.

Inspirados en los enciclopedistas, los padres de la independencia norteamericana ponian la idea de libertad por sobre todo, como verdad evidente e incontestable. Así lo expresa la Declaración de la Independencia, imbuída en el racionalismo y en la doctrina de derecho natural. Oponer la Constitución a las leyes anti-liberales es una valla de la sazón a la prepotencia de las mayorías eventuales. Significa situar la racionalidad por encima del voluntarismo político. Algo así como preferir la doctrina de Santo Tomás y de Suárez al voluntarismo popular, como podría observar el filósofo Bertrand Russell. 